\title{
COMUNICAÇÃO
}

\section{INQUÉRITO HELMINTOLÓGICO PELOS MÉTODOS DE KATO-KATZ, BAERMANN-MORAES E HARADA, EM TEFE E ALGUMAS LOCALIDADES DO RIO JAPURÁ-CAQUETÁ, AMAZONAS}

\section{Maria A. Millington, Carlos Henrique N. Costa, Antonio M. Tavares, Heitor Dourado, Willis A. Reid, Vanize Macedo e Aluízio Prata}

Em viagem ao Estado do Amazonas e limites com a Colômbia, em 1980, fizemos inquérito coprológico, para avaliar a prevalência de helmintoses intestinais.

Os exames foram realizados em Tefé, no Rio Solimões, em Maraã, Vila Japurá, Limoeiro e Vila Bittencourt, no Rio Japurá, localidades no Estado do Amazonas, Brasil e em Pedrera no Rio Caquetá, na Colômbia.

Foram examinadas 163 amostras de fezes, colhidas aleatoriamente, de individuos de ambos os sexos e de vários grupos etários:

$\begin{array}{cc}\text { Idade (anos) } & \text { Individuos (\%) } \\ 0-10 & 25,2 \\ 11-20 & 32,8 \\ 21-30 & 13,4 \\ 31-40 & 10,1 \\ 41-50 & 10,1 \\ 50 & 8,4\end{array}$

Os exames foram processados pelos métodos de Baermann-Moraes, de Kato modificado por Katz e de Harada

Em 142 exames realizados, pelo método de Kato-Katz, encontramos $123(86,66 \%)$ com ancilostomídeos, $114(80,2 \%)$ com Trichocephalus trichiurus e 94 (66,1\%) com Ascaris lumbricoides. A frequencia Strongyloides stercoralis foi de 57 (34,9\%) em 163 exames (Tabela 1).

A média de ovos de $A$. lumbricoides foi de $\bar{x}$ $28.012,4$, a de ancilostomídeos $\bar{x} 3.999,9$ e a de $T$. trichiurus $\bar{x}$ 1.582,01 (Tabela 2).

Entre os 49 exames positivos para ancilostomideos, pelo métudo de Harada, a prevalência de Necator americanus foi de 93,9 e a de Ancylostoma duodenale, 28,6\% (Tabela 3). A infecção apenas com uma das espécies de ancilostomideos ocorreu em $77,6 \%$ das amostras positivas, das quais $71,42 \%$ pelo $N$. americanus, e $6,12 \%$ pelo $A$. duodenale. A infecção mista foi registrada em apenas $22,44 \%$ dos casos positivos mas, com exceção de Vila Japurá, ocorreu em todas as localidades.

Tabela 1 - Resultados dos exames de fezes pelos métodos de Kato-Katz e Baermann-Moraes, em Tefe e localidades no Rio Japurá-Caquetá.

\begin{tabular}{lcccccc}
\hline Métodos & \multicolumn{3}{c}{ Kato-Katz } & \multicolumn{3}{c}{ Baermann-Moraes } \\
\cline { 2 - 7 } & $\begin{array}{c}\text { No } \\
\text { de } \\
\text { Lecalidades }\end{array}$ & $\begin{array}{c}\text { Ancilosto- } \\
\text { mideos } \\
\text { n.(\%) }\end{array}$ & $\begin{array}{c}\text { A. } \\
\text { lumbricoides } \\
\text { n. }(\%)\end{array}$ & $\begin{array}{c}\text { Tricoce- } \\
\text { falos } \\
\text { n. }(\%)\end{array}$ & $\begin{array}{c}\text { No. } \\
\text { de } \\
\text { exames }\end{array}$ & $\begin{array}{c}\text { Stercoralis } \\
\text { n.o (\%) }\end{array}$ \\
\hline Tefé & 22 & $18(81,8)$ & $16(72,7)$ & $13(59,0)$ & 23 & $5(21,7)$ \\
Maraã & 29 & $27(93,1)$ & $26(89,6)$ & $22(75,8)$ & 33 & $17(51,5)$ \\
Japurá & 44 & $42(95,4)$ & $33(75,0)$ & $43(97,7)$ & 51 & $24(47,0)$ \\
Limoeiro & 13 & $11(84,6)$ & $8(61,5)$ & $13(100,0)$ & 16 & $5(31,2)$ \\
V. Bittencourt & 22 & $13(59,0)$ & $9(40,9)$ & $12(54,5)$ & 25 & $3(12,0)$ \\
Pedrera & 12 & $12(100,0)$ & $2(16,6)$ & $11(91,6)$ & 15 & $3(20.0)$ \\
\hline Total & 142 & $123(86,6)$ & $94(66,2)$ & $114(80,2)$ & 163 & $57(34,9)$ \\
\hline
\end{tabular}

Núcleo de Medicina Tropical e Nutrição da Universidade de Brasilia e Instituto de Medicina Tropical de Manaus. Walter Reed Institute of Research. 
Comunicafao. Millington MA, Costa CHN, Tavares AM, Dourado H, Reid WA, Macedo V. Prata A. Inquerito helmintologico pelos metodos de Kato-Katz, Baermann-Moraes e Harada, em Tefe e algumas localidades do Rio Japura-Caqueta, Amazonas. Revista da Sociedade Brasileira de Medicina Tropical 22: 217-218, Out-Dez, 1989.

Tabela 2 - Média de ovos de helmintos por grama de fezes em Tefé e em localidades do Rio de Japurá-Caquetá.

\begin{tabular}{|c|c|c|c|c|c|c|c|}
\hline \multirow{3}{*}{$\begin{array}{l}\text { Localidades } \\
\text { Tefé }\end{array}$} & \multirow{3}{*}{$\begin{array}{c}\text { No } \\
\text { de exames }\end{array}$} & \multirow{2}{*}{\multicolumn{2}{|c|}{$\frac{\text { Ancilostomideos }}{\text { Pos. } / \overline{\mathrm{x}} \text { ovos }}$}} & \multirow{2}{*}{\multicolumn{2}{|c|}{$\frac{\text { Ascaris }}{\text { Pos.// } \text { ovos }}$}} & \multirow{2}{*}{\multicolumn{2}{|c|}{$\frac{\text { Tricocéfalos }}{\text { Pos. } / \overline{\mathrm{x}} \text { ovos }}$}} \\
\hline & & & & & & & \\
\hline & & 18 & $4.757,3$ & 16 & $21.256,8$ & 13 & $3.018,0$ \\
\hline Maraã & 29 & 27 & $4.757,3$ & 26 & $38.441,4$ & 22 & $1.572,0$ \\
\hline Japurá & 44 & 42 & $3.625,1$ & 33 & $19.459,6$ & 43 & $1.786,6$ \\
\hline Limoeiro & 13 & 11 & $5.584,7$ & 8 & $33.333,5$ & 13 & 989.5 \\
\hline V. Bittencourt & 22 & 13 & 615,7 & 9 & $26.818,6$ & 12 & 652,3 \\
\hline Pedrera & 12 & 12 & $4.337,3$ & 2 & $71.692,0$ & 11 & 821.4 \\
\hline Total & 142 & 123 & $3.999,9$ & 94 & $28.012,4$ & 114 & 1.582 .0 \\
\hline
\end{tabular}

Tabela 3 - Freqüência de A. duodenale e N. americanus, pelo metodo de Harada. em Tefe e localidades do Rio Jạpurá

\begin{tabular}{lcccc}
\hline Localidades & $\begin{array}{c}\text { Exames } \\
\text { realizados }\end{array}$ & $\begin{array}{c}\text { N. americanus } \\
\text { no(\%) }\end{array}$ & $\begin{array}{c}\text { A. duodenale } \\
\text { no }(\%)\end{array}$ & $\begin{array}{c}\text { Ambos } \\
\text { n.' }(\%)\end{array}$ \\
\hline Tefé & 17 & $5(29,4)$ & $1(5.9)$ & $5(29.4)$ \\
Maraã & 12 & $7(58.3)$ & $1(8.3)$ & $3(25.0)$ \\
Japurá & 24 & $13(54.1)$ & 0 & 0 \\
Limoeiro & 5 & $2(40.0)$ & 0 & $1,20.01$ \\
V. Bittencourt & 22 & $8(36,4)$ & $1(4.5)$ & $2,9.1)$ \\
\hline Total & 80 & $35(43.7)$ & $3,3.7$ & $11(13.7)$ \\
\hline
\end{tabular}

